\title{
Assess Knowledge, Attitude and Practice Regarding Cigarette and Other Tobacco Products Act (COTPA) and Tobacco Related Health Problems in Rural Setting of Bihar, India
}

\author{
Article by Rajendra Kumar Singh \\ $M B B S, B$. N. Mandal University, India \\ Master of Public Health (MPH), Texila American University, India \\ E-mail: singh.rajendra2727@gmail.com
}

\begin{abstract}
Tobacco addiction is most widespread addiction and it is the most important cause of death in the world. A cross sectional community based study was conducted in Buxar district of Bihar to assess knowledge, attitude and practice regarding Cigarette and Other Tobacco Products Act (COTPA) and tobacco related health problems in rural setting of Bihar, India. Data regarding awareness about tobacco control law in India, tobacco related health problems, attitude regarding tobacco control law and information on tobacco use were collected by interview method using a questionnaire.

The study shows that awareness of COTPA is low, although knowledge and perception about certain components of the COTPA is relatively higher. Attitude and beliefs of participants regarding COTPA showed that at least half of the participants agreeing that provisions were successful in curbing the consumption of tobacco. The mean scores for knowledge, attitude and practice section did not show any statistically significant difference between tobacco users and non-tobacco users after adjusting for sex, age group, occupation. The data shows significant difference in mean score of attitude section between tobacco users and non-users after adjusting for the education status of the individual, no such difference in seen in knowledge and practice totals.

The survey has pinpointed clear areas where a huge gap in knowledge exists; which could be fixed by effective public private partnership. The availability of adequate knowledge and information will lead to change in the attitude regarding consumption of tobacco products in rural India.

A cross Sectional Study in rural population for knowledge, Attitude and Practice of Cigarettes and Other Tobacco Products Act among population of Simri village of Simri Block in Buxar district of Bihar in India.
\end{abstract}

\section{Introduction}

Tobacco contributes to 5 million deaths per year globally. According to World Health Organization (WHO), tobacco kills more people annually than AIDS, alcohol, other addictions (drugs) and accidents put together and this figure is expected to rise to 10 million tobacco deaths annually by 2025 . Five hundred million die prematurely due to tobacco use; most of these are children and young adults of today. One-fifth of all worldwide deaths attributed to tobacco occur in India; more than 8,00,000 people die and 12 million people fall ill due to tobacco use each year(1). Tobacco addiction is the most widespread addiction in the world. There are nearly 1.3 billion smokers in the world, $80 \%$ of them are in the developing countries. India has more than 300 million smokers. Tobacco use is the leading cause of death in the world (2). Tobacco is the only legally available consumer product which kills people when it is used entirely as intended (3).

In India, beedi smoking is the most popular form of tobacco smoking (54\%); cigarette smoking is the second most popular form of tobacco smoking (16\%); while tobacco chewing accounts for $30 \%$ of the total consumption(2). Pan with tobacco is the major chewing form of tobacco. Dry tobacco, areca nut preparations such as pan masala, gutkha and khaini are also 
Texila International Journal of Public Health

Volume 4, Issue 4, Dec 2016

popular and highly addictive. Knowledge attitude and practices regarding the cigarettes and other tobacco products act (COTPA) in Simri village of Simri Block in Buxar District of Biharin India. Awareness about hazardous health effects of tobacco has increased over time owing to widespread campaigns in media, but its role alone towards attainment of tobacco free India remains questionable.

Although, the tobacco industry claims it creates jobs and generates revenues that enhance local and national economies, the industry's overriding contribution to any country is suffering, disease, death - and economic losses. Tobacco use currently costs the world hundreds of billions of dollars each year (4). Several negotiations later, the World Health Assembly in May 2003 finally adopted the Framework Convention on Tobacco Control (FCTC), which has provisions for members to have comprehensive legislation to curb the tobacco epidemic. India was one of the first few countries that ratified the FCTC (5). The Government of India formulated "The Cigarettes and Other Tobacco Products (Prohibition of Advertisement and Regulation of Trade and Commerce, Production, Supply, and Distribution) Act (COTPA)" on May 18, 2003. In 2004, the rules regarding COTPA provisions were notified. As per the act, smoking is prohibited in all public places; ban is placed on advertisements of tobacco products, and prohibition of sale of tobacco products to minors and within 100 yards of educational institutions (6). The implementation of this law remained largely ineffective in the initial years. The Government of India reviewed the situation and revised the law, with effect from 2nd October 2008, making additional provisions to improve the implementation of smoke free law (7). Not many studies have been done on awareness and attitudes of the general public regarding Cigarettes and Other Tobacco Products Act (COTPA). For effective implementation of Tobacco control knowledge regarding the awareness, attitudes and practices of the population towards tobacco control is necessary. Hence the present study was undertaken among adults in Simri Block of Buxar District of Bihar with an aim to find the awareness, attitudes and practices regarding Cigarettes and Other Tobacco Products Act (COTPA).

\section{Aims and objective}

The study is planned in one rural setting to know the gap in knowledge, awareness and practice related to COTPA and also to access any change in trends of its (Tobacco) consumption

\section{Material and methods}

\section{Study design}

The present study is a cross-sectional community based survey, will be carried out in Simri Block of Buxar District of Bihar. The study will be carried out in the year 2016. The study will be included Male adults 18 years and above, who were voluntarily willing to participate. Written informed consent will be obtained long with the interview from all the participants. Female are not participate in study due to less (Only 3\%) Females' smokers in India according to WHO report.

\section{Sample size and study area}

Calculation of sample size was done to ensure the minimum number of Persons needed to be a representative sample for the whole population of Simri Village of Simri block in buxar District ofBihar in India. The sample size was determined using Formula implemented in cross sectional study on NCBI website (8). Total population size of Simri village is 9756 peoples, analyze sample size Keeping an confidence level 95\% and Margin of error 5\%, the calculated sample size is 323 persons. But we considered sample size for study is 350 .

Formula:

$$
\text { Sample Size }=\frac{Z_{1-\alpha / 2}^{2} p(1-p)}{d^{2}}
$$

Where, 
$\mathrm{Z}_{1-\alpha / 2}^{2}=$ Is standard normal Variate (at $5 \%$ type 1 error $(\mathrm{p}<0.05)$ it is 1 . As in majority of studies $\mathrm{P}$ values are considered significant below 0.05 hence 1.96 is used in formula.

$\mathrm{P}=$ Expected proportion in population based on smoking percentage given by WHO (smoking in India is $30 \%=0.30$ )

$\mathrm{d}=$ Absolute error of precision $(5 \%)$

Sample Size $=\frac{(1.96)^{2} \times 0.30(1-0.30)}{5}=322.69(323)$

\section{Demography of simri}

Simriis a large village located in Simri Block of Buxar district. The Simri village has population of 9756 of as per Population Census 2011. Simri Block has higher literacy rate compared to Bihar. In 2011, literacy rate of Simri Block was $73.28 \%$ compared to $61.80 \%$ of Bihar.

Table showing rural areas

\begin{tabular}{|l|l|l|l|c|}
\hline $\begin{array}{c}\text { Name of District / Sub- } \\
\text { division }\end{array}$ & $\begin{array}{c}\text { Name of } \\
\text { Blocks }\end{array}$ & $\begin{array}{c}\text { Name of Village } \\
\text { Population }\end{array}$ & Population & $\begin{array}{c}\text { Sample } \\
\text { size }\end{array}$ \\
\hline Buxar / Dumraon & Simri & Simri & 9756 & 350 \\
\hline
\end{tabular}

\section{Data collection}

The data was collected using a structured schedule by interviewing the study participants in the local language. Information on socio-demographic variables, educational status, occupation and monthly incomes will also obtain. Data on awareness about any tobacco control law in India, tobacco related health problems, perceptions about secondhand smoke, attitude towards the tobacco control law and information about use of tobacco will collect. The schedule includes Seven questions to assess the awareness/knowledge level of adults regarding COTPA, which will be two choices i.e., Yes or No. Five questions to assess attitude towards the COTPA, which will be two choices i.e. P(positive) or N(negative) and Five questions to assess practice towards the COTPA, which will be two choices i.e., Yes or No. The choices will be given a score from 1 and 5 .

For every Yes or Positive response, a score of one will be allotted and responses other than mentioned earlier will score Zero. Thus, a maximum score of 7 can be achieved in knowledge part, 5 in attitude and 5 in practice.

\section{Data analysis}

Statistical analysis was done using SPSS version 11.0, after entering the data in Microsoft Office Excel, 2007. Proportions, percentages and Odds ratio will be calculated for relevant variables. A $p$ value of $<0.05$ will be consider statistically significant.

\section{Result:}

Awareness about COTPA among general population in a rural setting is good enough and people have positive attitude about COTPA and they feel that it will reduce burden of Tobacco user. The real problem is in its implementation by the lawmakers and general administration. As a result being quite felt presence of messages of tobacco and its health hazards, COTPA is not getting proportionate success.

Political commitment and legislative support is very much needed to reduce bad effects of tobacco and its products over general population.

There must be monthly progress tracking of COTPA at district and sub district level and responsibility to be fixed with timeline.

It must be reviewed at every level as an important indicator of effectiveness of public health program.

There are many local processing units of tobacco which sells tobacco in form of Kahiani and Bidi, without any warning label must be taken care by law enforcing agencies for labeling the products with warnings as pr norms. 
Texila International Journal of Public Health

Volume 4, Issue 4, Dec 2016

Further research is needed to know effectiveness of COTPA in Urban setting.

\section{Discussion}

We were able to successfully conduct the survey with the target sample size of 350 participants in Simri Village of Simri block in Buxar District of Bihar. Out of the 350 participants interviewed 336 (96\%) were male and 14 (4\%) were female. The majority of participants who volunteered for the survey were between ages 18-29 (46.3\%) and the least number of participants were between ages 50-59 (3.1\%). The data shows that 321 (91.7\%) participants had attained at least high school education and only 29 (8.3\%) participants had an educational level lower than High school. The occupation of participants in the survey was as follows: $53(15.1 \%)$ participants were unemployed at the time of the interview, 7 (2\%) worked as laborer or Peon, $62(17.7 \%)$ participants worked as Shopkeeper/Businessman, 97 (27.7\%) participants worked as government officials or teacher and $131(37.4 \%)$ participants worked as farmer. There were 298 (85.1\%) participants who used one or the other form of tobacco products and $52(14.9 \%)$ participants did not use any tobacco products.

We are glad to point out that all 17 questions in the 350 surveys conducted were answered by the participants. Table __ shows the response for each survey question. Looking at the response to the Knowledge of COTPA section of the survey, we see that $121(34.6 \%)$ of participants knew about the act, 131 (37.4\%) participants knew about the penalty for violation of the act, $258(73.7 \%)$ participants knew that sale of tobacco products near educational institution was banned, 205 (58.6\%) participants knew that sale of tobacco products to minors was banned, only $114(32.6 \%)$ participants had seen any warning on tobacco products, $188(53.7 \%)$ participants were aware of tobacco consumption related health problems and only 117 (33.4\%) participants were aware of harmful effects of second hand smoke. The response from the section about the attitude against COTPA shows that $180(51.4 \%)$ participants felt that COTPA will be successful in reducing tobacco use, $175(50 \%)$ participants felt that the ban of sale of tobacco products to minor will be effective in controlling tobacco use, $162(46.3 \%)$ participants felt that the ban on tobacco sale near educational institution will have impact on controlling tobacco use among minors, $172(49.1 \%)$ participants felt that the health warnings on tobacco products will have positive impact on controlling the consumption and $184(52.6 \%)$ participants felt that objection against use of the tobacco products in public places would reduce the consumption of tobacco. The response from the section on Practice of COTPA shows that only 92 (26.3\%) participants had seen a poster/billboard regarding COTPA, $229(65.4 \%)$ participants had heard of fine being imposed for smoking in public places, 197 (56.3\%) participants knew about the fine amount, $183(52.3 \%)$ participants had seen an advertisement about COTPA in print or electronic media and $303(86.6 \%)$ participants had seen warnings signs regarding sale of tobacco products to minors at selling points. Further subgroup analysis was performed for each question of the questionnaire to detect any difference in response, but no significant difference in response to the questionnaire was observed during this analysis.

The scoring method and maximum and minimum score for all three sections of the questionnaire have already been discussed in the data collection section. The mean score for was calculated for all the three sections based on response from the participants. Table 3 shows the mean and standard deviation of the total score for each section. The table 3 also shows the mean and standard deviation amongst tobacco user and nontobacco users for the three sections of the questionnaire. The comparison of mean total scores of the knowledge, attitude and practice sections amongst tobacco users and nontobacco users shows no statistically significant difference $(p>0.05)$. The mean scores for knowledge, attitude and practice section did not show any statistically significant difference between tobacco users and non-tobacco users after adjusting for sex, age group, occupation. The data shows significant difference in mean score of attitude 
section between tobacco users and non-users after adjusting for the education status of the individual, no such difference in seen in knowledge and practice totals.

\section{Conclusion}

The data shows that the awareness of COTPA is low amongst the residents of Simri Village, although knowledge and perception about certain components of the COTPA is relatively higher. It was surprising to know that only $32.6 \%$ participants had seen any warning signs on tobacco products. This could be linked to local products not displaying the required warning signs. This is an area of great concern that needs to be addressed. The survey shows that attitude and beliefs of participants regarding COTPA showed a positive outlook with at least half of the participants agreeing that provisions under COTPA were successful in curbing the consumption of tobacco. The section on practice of COTPA showed us that the information was reaching participants by some or the other medium. The display of information about COTPA in public places could be increased which could lead to greater awareness and could effectively reduce the consumption of tobacco products in public places. A large number of participants have seen the warning signs at the selling point which could be very effective in reducing the consumption of tobacco amongst the minors.

The survey gives us a glimmer of hope regarding effectiveness of COTPA in curbing tobacco consumption in rural India. The survey has provided us with a great deal of valuable information regarding gaps in implementation of COTPA in rural area like Simri village of Simri block in Buxar district of Bihar. The survey has pinpointed clear areas where a huge gap in knowledge exists; this could be fixed by effective public and private partnership. The increase in knowledge about COTPA and tobacco related health problems could greatly improve the chances of reducing tobacco consumption in rural India. The availability of adequate knowledge and information will lead to change in the attitude regarding consumption of tobacco products in rural India. The government in currently investing a large amount of resources in tobacco control efforts but the reach of such efforts to most vulnerable sections of society i.e. rural India is questionable based on the results of the survey. There are numerous platforms in rural India that could be utilized to convey the message in a very effective way and the government and numerous organizations need to utilize these platforms to targets the population of rural India. I would like to repeat the survey in future in an urban region of Bihar to compare and contrast the findings with the current survey.

I would like to point out a few limitations of the survey that need to be noted before inferring the data presented. The survey was conducted in a single village of Bihar and although best efforts were made to get a random sample of participants for the survey there were few constraints which made it difficult. A large proportion of participants were tobacco user and so some bias might be introduced as consumers of tobacco are more prone to recall certain information as compared to non-users. The other important point that needs to be considered is the literacy rate in Simri block of Bihar, which is higher than the state average. This could lead to positive scores in all the section of survey and great care needs to be taken before utilizing the survey data for program planning in other regions. Even though the above mentioned limitations prevent generalizability of the survey data, we do get a great picture of current status of knowledge, attitude and practice regarding COTPA and tobacco consumption in rural India. The survey needs to be further administered in various rural areas across India to get high quality data to identify areas of gap and need. 
Texila International Journal of Public Health

Volume 4, Issue 4, Dec 2016

Tables

Table 1. Demographic information of Study Participants:

\begin{tabular}{|c|c|c|c|c|c|c|}
\hline & \multicolumn{2}{|c|}{ Tobacco User } & \multicolumn{2}{|c|}{$\begin{array}{c}\text { Non Tobacco } \\
\text { User }\end{array}$} & \multicolumn{2}{|c|}{ Total } \\
\hline & $\mathbf{N}$ & $\%$ & $\mathbf{N}$ & $\%$ & $\mathbf{N}$ & $\%$ \\
\hline \multicolumn{7}{|l|}{ Sex } \\
\hline Male & 286 & $85.1 \%$ & 50 & $14.9 \%$ & 336 & $96.0 \%$ \\
\hline Female & 12 & $85.7 \%$ & 2 & $14.3 \%$ & 14 & $4.0 \%$ \\
\hline \multicolumn{7}{|l|}{ Age Group } \\
\hline $18-29$ & 139 & $85.8 \%$ & 23 & $14.2 \%$ & 162 & $46.3 \%$ \\
\hline 30-39 & 82 & $82.8 \%$ & 17 & $17.2 \%$ & 99 & $28.3 \%$ \\
\hline $40-49$ & 68 & $87.2 \%$ & 10 & $12.8 \%$ & 78 & $22.3 \%$ \\
\hline $50-59$ & 9 & $81.8 \%$ & 2 & $18.2 \%$ & 11 & $3.1 \%$ \\
\hline \multicolumn{7}{|l|}{ Educational Status } \\
\hline Lower Primary & 7 & $77.8 \%$ & 2 & $22.2 \%$ & 9 & $2.6 \%$ \\
\hline Higher Primary & 18 & $90.0 \%$ & 2 & $10.0 \%$ & 20 & $5.7 \%$ \\
\hline High School & 196 & $84.1 \%$ & 37 & $15.9 \%$ & 233 & $66.6 \%$ \\
\hline College & 62 & $88.6 \%$ & 8 & $11.4 \%$ & 70 & $20.0 \%$ \\
\hline Degree and above & 15 & $83.3 \%$ & 3 & $16.7 \%$ & 18 & $5.1 \%$ \\
\hline \multicolumn{7}{|l|}{ Occupation } \\
\hline Un Employed & 47 & $88.7 \%$ & 6 & $11.3 \%$ & 53 & $15.1 \%$ \\
\hline Labour/Peon & 7 & $100.0 \%$ & 0 & $0.0 \%$ & 7 & $2.0 \%$ \\
\hline Shopkeeper/Businessman & 52 & $83.9 \%$ & 10 & $16.1 \%$ & 62 & $17.7 \%$ \\
\hline $\begin{array}{l}\text { Government } \\
\text { Officials/Teacher }\end{array}$ & 78 & $80.4 \%$ & 19 & $19.6 \%$ & 97 & $27.7 \%$ \\
\hline Farmer & 114 & $87.0 \%$ & 17 & $13.0 \%$ & 131 & $37.4 \%$ \\
\hline N (Total) & 298 & $85.1 \%$ & 52 & $14.9 \%$ & 350 & $100.0 \%$ \\
\hline
\end{tabular}

Table 2. Response to Knowledge, attitude and practice sections of questionnaire by Participants:

\begin{tabular}{|l|c|c|c|c|}
\hline \multirow{2}{*}{ Response } & \multicolumn{2}{c|}{ Yes/Positive } & \multicolumn{2}{c|}{ No/Negative } \\
\cline { 2 - 5 } & $\mathbf{N}$ & $\mathbf{\%}$ & $\mathbf{N}$ & $\mathbf{\%}$ \\
\hline \multicolumn{1}{|c|}{ Knowledge of COTPA } & & & & \\
\hline $\begin{array}{l}\text { Do you know about any Act/Legislation } \\
\text { regarding tobacco products (COTPA)? (YES / } \\
\text { NO) }\end{array}$ & 121 & $34.6 \%$ & 229 & $65.4 \%$ \\
\hline $\begin{array}{l}\text { Do you know about penalty for violation of } \\
\text { Act? (YES / NO) }\end{array}$ & 131 & $37.4 \%$ & 219 & $62.6 \%$ \\
\hline $\begin{array}{l}\text { Do you know that there is ban on selling } \\
\text { tobacco products near educational institutes? } \\
\text { YES / NO }\end{array}$ & 258 & $73.7 \%$ & 92 & $26.3 \%$ \\
\hline $\begin{array}{l}\text { Do you know that there is ban on sale of } \\
\text { tobacco products to minors? (YES / NO) }\end{array}$ & 205 & $58.6 \%$ & 145 & $41.4 \%$ \\
\hline
\end{tabular}


Texila International Journal of Public Health

Volume 4, Issue 4, Dec 2016

\begin{tabular}{|c|c|c|c|c|}
\hline $\begin{array}{l}\text { Have you seen any warnings on tobacco } \\
\text { products (YES / NO) }\end{array}$ & 114 & $32.6 \%$ & 236 & $67.4 \%$ \\
\hline $\begin{array}{l}\text { Are you aware about any tobacco related } \\
\text { health problems (like-Cancer, Respiratory } \\
\text { disease, Heart disease, Tuberculosis, } \\
\text { Hypertension, All of the above) (YES / NO) }\end{array}$ & 188 & $53.7 \%$ & 162 & $46.3 \%$ \\
\hline $\begin{array}{l}\text { Are you aware about harmful effects of } \\
\text { second hand smoke (YES / NO) }\end{array}$ & 117 & $33.4 \%$ & 233 & $66.6 \%$ \\
\hline \multicolumn{5}{|l|}{ Attitude against COTPA } \\
\hline $\begin{array}{l}\text { Do you think COTPA will be successful in } \\
\text { banning tobacco use? }(\mathrm{P} / \mathrm{N})\end{array}$ & 180 & $51.4 \%$ & 170 & $48.6 \%$ \\
\hline $\begin{array}{l}\text { Do you think that ban on selling tobacco } \\
\text { products to minors will be effective in } \\
\text { controlling tobacco use? }(\mathrm{P} / \mathrm{N})\end{array}$ & 175 & $50.0 \%$ & 175 & $50.0 \%$ \\
\hline $\begin{array}{l}\text { Is banning tobacco sell near educational } \\
\text { premises will have impact on controlling } \\
\text { tobacco use among minors? }(\mathrm{P} / \mathrm{N})\end{array}$ & 162 & $46.3 \%$ & 188 & $53.7 \%$ \\
\hline $\begin{array}{l}\text { Do you think that health warnings on tobacco } \\
\text { products will have any impact? }(\mathrm{P} / \mathrm{N})\end{array}$ & 172 & $49.1 \%$ & 178 & $50.9 \%$ \\
\hline $\begin{array}{l}\text { Do you think objecting other person will } \\
\text { reduce tobacco use in public places? }(\mathrm{P} / \mathrm{N})\end{array}$ & 184 & $52.6 \%$ & 166 & $47.4 \%$ \\
\hline \multicolumn{5}{|l|}{ Practice of COTPA } \\
\hline $\begin{array}{l}\text { Have you seen any poster/billboard regarding } \\
\text { COTPA in public places? (Yes/No) }\end{array}$ & 92 & $26.3 \%$ & 258 & $73.7 \%$ \\
\hline $\begin{array}{l}\text { Have you heard of fine being imposed on any } \\
\text { smoker by govt. agencies for using tobacco in } \\
\text { public places? (Yes/No) }\end{array}$ & 229 & $65.4 \%$ & 121 & $34.6 \%$ \\
\hline $\begin{array}{l}\text { Do you know regarding penalty or fine amount } \\
\text { by any mode? (Yes/No) }\end{array}$ & 197 & $56.3 \%$ & 153 & $43.7 \%$ \\
\hline $\begin{array}{l}\text { Have you seen any advertisement in print and } \\
\text { electronic media regarding COTPA? (Yes/No) }\end{array}$ & 183 & $52.3 \%$ & 167 & $47.7 \%$ \\
\hline $\begin{array}{l}\text { Have you ever seen any signage regarding } \\
\text { warnings of Tobacco use among minors at } \\
\text { selling points ?(Yes/No) }\end{array}$ & 303 & $86.6 \%$ & 47 & $13.4 \%$ \\
\hline
\end{tabular}




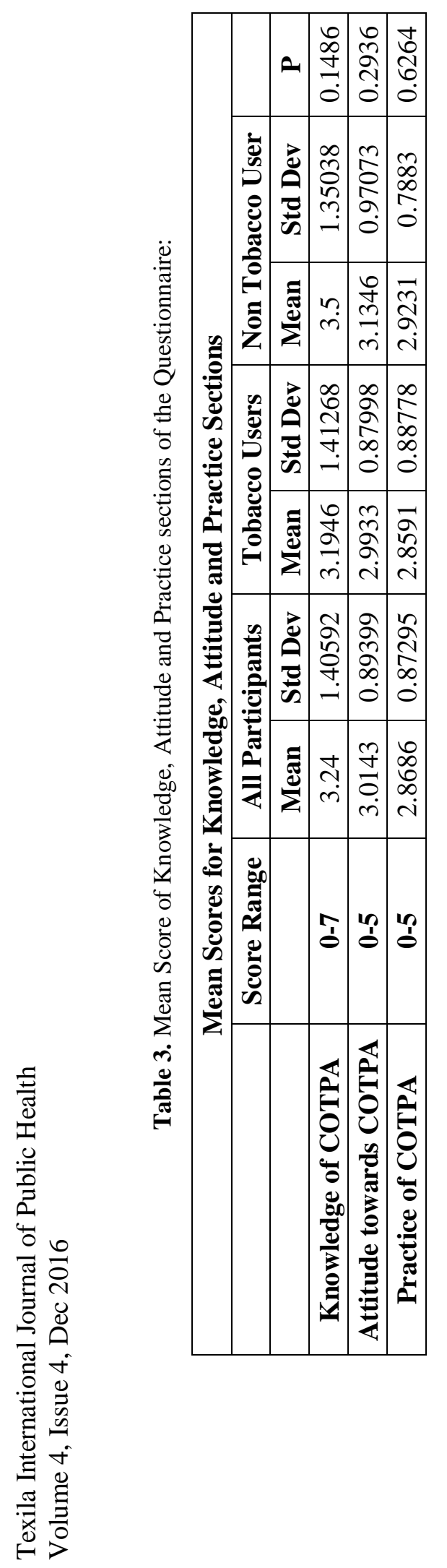




\section{References}

[1] Guindon GE et al. The cost attributable to tobacco use: a critical review of the literature. Geneva, World Health Organization, 2006.

[2] https://www.rit.edu/research/hsro/informed_consent_document_sample_tips

[3] Mackay, Judith / Eriksen, Michael (2002): The Tobacco Atlas. Geneva, The World Health Organization (WHO).

[4] Resource centre for tobacco free India; an initiative of Voluntary Health Association of India,[cited2013Sep1]Available

[5] Tobacco control foundation of India, Tobacco facts, [cited $2013 \mathrm{Sep}$ 1] available from http://tobaccoindia.org/Tobacco-Facts.html

[6] The Cigarettes and Other Tobacco Products (Prohibition of Advertisement and Regulation of Trade and Commerce, Production, Supply, and Distribution) Act, 2003. New Delhi, India: Government of India;2003.

[7] The Cigarettes and Other Tobacco Products (Prohibition of Advertisement and Regulation of Trade and Commerce, Production, Supply, and Distribution) Act, Amendment Bill, 2007. New Delhi, India: Government of India;2007.

[8] Walton J, Barondess JA, Lock S. The Oxford Medical Companion. 1st ed. USA: Oxford University Press: 1994.

[9] WHO Framework Convention on Tobacco Control, WHO, Geneva, Switzerland. [cited2013Sep1] available from http://www.who.int/tobacco/framework/WHO_FCT C_english.pdf 